\title{
Two-body wear behavior of human enamel versus monolithic zirconia, lithium disilicate, ceramometal and composite resin
}

\author{
Syed Rashid Habibi* ${ }^{*}$, Abdulaziz Alotaibi², Nawaf Al Hazza ${ }^{2}$, Yasser Allam², Mohammad AlGhazi² \\ ${ }^{1}$ Department of Prosthetic Dental Sciences, College of Dentistry, King Saud University, Riyadh, Saudi Arabia \\ ${ }^{2}$ College of Dentistry, King Saud University, Riyadh, Saudi Arabia
}

\begin{abstract}
PURPOSE. To investigate and compare the surface roughness (SR), weight and height of monolithic zirconia $(\mathrm{MZ})$, ceramometal $(\mathrm{CM})$, lithium disilicate glass ceramic (LD), composite resin (CR), and their antagonistic human teeth enamel. MATERIALS AND METHODS. 32 disc shaped specimens for the four test materials $(n=8)$ and 32 premolars were prepared and randomly divided. SR, weight and height of the materials and the antagonist enamel were recorded before and after subjecting the specimens to 240,000 wear-cycles (49 N/0.8 $\left.\mathrm{Hz} / 5^{\circ} \mathrm{C} / 50^{\circ} \mathrm{C}\right)$. SR, height, weight, and digital microscopic qualitative evaluation were measured. RESULTS. CM $(0.23+0.08 \mu \mathrm{m})$ and $\mathrm{LD}(0.68+0.16 \mu \mathrm{m})$ exhibited the least and highest mean difference in the SR, respectively. ANOVA revealed significance $(P=.001)$ between the materials for the SR. Paired T-Test showed significance $(P<.05)$ for the pre- and post- SR for all the materials. For the antagonistic enamel, no significance $(P=.987)$ was found between the groups. However, the pre- and post- SR values of all the enamel groups were significant $(P<.05)$. Wear cycles had significant effect on enamel weight loss against all the materials $(P<.05)$. CR and $M Z$ showed the lowest and highest height loss of $0.14 \mathrm{~mm}$ and $0.46 \mathrm{~mm}$, respectively. CONCLUSION. MZ and CM are more resistant to SR against the enamel than LD and CR. Enamel worn against test materials showed similar SR. Significant variations in SR values for the tested materials (MZ, LD, CM, and CR) against the enamel were found. Wear simulation significantly affected the enamel weight loss against all the materials, and enamel antagonist against MZ and CM showed more height loss. [J Adv Prosthodont 2019;11:23-31]
\end{abstract}

KEYWORDS: Dental wear; Monolithic zirconia; Enamel wear; Ceramic wear; Wear behavior; Surface roughness

\section{INTRODUCTION}

Tooth wear is a term to describe the progressive loss of a tooth's surface due to various factors except tooth decay. It can cause many clinical problems including enamel loss, loss

Corresponding author:

Syed Rashid Habib

Department of Prosthetic Dental Sciences, College of Dentistry, King Saud University, P. O. Box 60169, King Abdullah Road, Riyadh, 11545, Saudi Arabia

Tel.+96614677441: e-mail, rashidhabib@hotmail.com

Received May 13, 2018 / Last Revision October 4, 2018 / Accepted January 21, 2019

(C) 2019 The Korean Academy of Prosthodontics

This is an Open Access article distributed under the terms of the Creative Commons Attribution Non-Commercial License (http://creativecommons. org/licenses/by-nc/4.0) which permits unrestricted non-commercial use, distribution, and reproduction in any medium, provided the original work is properly cited.

The research project was approved and supported by the College of Dentistry Research Center (CDRC Registration \# IR0255; IRB Project No. E-17-2705) and Deanship of Scientific Research at King Saud University. of vertical dimension, problems in mastication, temporomandibular disorders, hypersensitivity, and esthetic impairment. ${ }^{1}$ Tooth wear is classified into erosion which is caused by exposure to acids, attrition which is loss of tooth structure by mechanical forces from the opposing teeth, abrasion which is produced by interaction between tooth surface and other materials, and abfraction which might potentiate wear by abrasion and/or erosion. ${ }^{2}$ Tooth wear may result from abrasive content of foods and harmful habits such as aggressive tooth brushing, clenching/bruxism, and it may also vary due to different types of dental restorations. The annual wear rate of sound enamel under friction from mastication has been reported to range between $20 \mu \mathrm{m}$ and 40 $\mu \mathrm{m} .^{3}$

Different materials, including composite-resin, metals, ceramics and combination of metals and ceramics are used to fabricate extra/intra coronal restorations. In the past, ceramic crowns had inferior tensile strength, hardness, brittleness, and resistance to fracture. ${ }^{4}$ Recent developments 
have led to ceramic restorations with improved physical properties. New low-fusing ceramic materials are reported to be more wear-friendly because of their lower hardness, lower concentrations of crystal phase, and smaller crystal size. $^{5,6}$ Ceramics are known for its high biocompatibility, strength, high esthetics, and characteristics similar to human enamel. However, ceramic materials cause increased wear of the opposing enamel compared to other restorative materials in general, which is still a concern for researchers. ${ }^{7,8}$

Composite resin materials used for the restoration of the posterior teeth can also cause wear of enamel. This wear is dependent on the particles size, hardness, and the filler contents of the composites. Newly developed composite resin materials claim to possess high resistance to wear because of the improvement in filler quality and chemical composition of resin matrix. Composite resins with particle size less than $1 \mu \mathrm{m}$ has been found to be more wear resistant. ${ }^{7,9,10} \mathrm{~A}$ recent retrospective study by Bartlett and Varma ${ }^{11}$ revealed high success rate of resin composites with latest bonding systems of up to 12 -year survival time in function. Composites for restoring the lost tooth surface are economical and conservative compared to ceramics, which is expensive, requires more tooth preparation, and can lead to pulpal complications. ${ }^{11-13}$

Lithium disilicate is one of the more widely used and widely known type of glass ceramics. It is formed by adding lithium oxide to alumina-silicate glass to enhance the mechanical properties. ${ }^{14}$ All ceramic lithium disilicate crowns have high survival rates and have been successfully used for single crowns and multiple unit fixed partial dentures. Lithium disilicate has superior mechanical properties compared to conventional feldspathic porcelain with a flexural strength of 0.28 $\mathrm{GPa}$ and fracture toughness of $\mathrm{KIC}=2.75 \mathrm{MN} / \mathrm{m}^{3 / 2} .{ }^{15,16}$

The wear behavior of the ceramics is different from that of the metal or composite resin. Ceramics and enamel wears through a micro fracture mechanism while the composite resins wear through fatigue wear and abrasion., ${ }^{7,17,18}$ According to Fischer et al., ${ }^{19}$ the wear resistance is directly associated with the hardness. However, other researchers have found the SR and fracture toughness to be the primary reasons for the wear, not hardness values. ${ }^{20,21}$

Oxide ceramics, zirconia in particular, are popular because of its excellent biocompatibility, high strength, and improved load bearing property. Prospective studies reported about reliable clinical results of 3 and 4 units fixed partial denture prosthesis with frameworks made of zirconia. ${ }^{22,23}$ The common problems were the chipping/fracture of veneering ceramic. In order to avoid these complications, zirconia with anatomic contours called monolithic zirconia without the need for veneering ceramic was introduced. This newly developed material enables esthetic improvement and increased strength without the need for veneering ceramic. Improvements in the mechanical properties are supposed to affect the wear behavior of these monolithic zirconia. ${ }^{24,25}$

Ideally, the wear resistance of the restorative material and enamel should be similar. The wear that occurs between the enamel of natural teeth and restorations should be considered in the selection of restorative materials. The complexity of the wear process and its measurement in the oral environment makes it very difficult to conduct in vivo toothwear studies. However, to overcome the difficulties in in vivo methods, wear simulators and methods have been developed to study the wear behavior of dental restorative materials in vitro. Advances in current technology have enabled simulation of human chewing cycle in a laboratory using specific loads and frictional forces exerted by a chewing simulator and determination of the surface profile of worn materials by using a 3D Profilometer. ${ }^{79,13,21,22,24,25}$

The aim of this in vitro research project was to investigate and compare the SR, weight, and height of four restorative materials; MZ, CM, LD, CR, and their antagonistic human teeth enamel before and after aging in a reciprocating sliding wear chewing simulator. The null hypotheses were that the materials tested and their antagonistic enamel would show similar SR, weight loss, and height loss values after the wear cycles.

\section{MATERIALS AND METHODS}

Before the study began, ethical clearance (IRB \# E-17-2705) was obtained from the ethics committee of Institutional Review Board of King Saud University Medical City (KSUMC). The study was conducted from November 2017 to March 2018 at the department of prosthetic dental sciences in collaboration with college of dentistry research center, (CDRC registration \# IR0255) College of Dentistry, King Saud University.

This in vitro study tested the two-body wear of four restorative materials $(\mathrm{n}=8)$; MZ, $\mathrm{LD}, \mathrm{CM}, \mathrm{CR}$, and their enamel antagonists using multifunctional chewing simulator (Chewing Simulator, CS-4.8 professional line, SD Mechatronik $\mathrm{GmbH}$, Westerham, Germany). Table 1 provides detailed information of the materials used in the study. The sample size of 8 per group was selected based on the specimen capacity of the multifunctional chewing simulator machine. Also, at significance of 0.05 with estimated standard deviation, power, and maximum difference of $0.3,0.96$, and 0.7 , respectively, the sample size for each group was supposed to be at least 8 . Previous studies ${ }^{26}$ also observed the sample size of 8 per group to be sufficient for wear studies using chewing simulation under standardized controlled environment.

The enamel specimens included 32 premolars that were recently extracted for orthodontic purpose. Only teeth with sound enamel over the cusps were selected, and teeth with worn-out cusps, caries or fracture were excluded. The teeth after collection were stored in water containing $0.05 \%$ thymol to simulate the intraoral condition and used as samples within thirty days after the extraction. Due to variations in the sizes of the teeth, to standardize the mounting for simulation machine holder, they were embedded in acrylic resin (Ortho-Resin, DeguDent GmbH, Hanau, Germany) mold up to the cemento-enamel junction (Fig. 1A). 32 samples 
Table 1. The test groups, abbreviations, brands, batch numbers and manufacturers of the tested materials $(\mathrm{N}=32)$

\begin{tabular}{lllcl}
\hline \multicolumn{1}{c}{ Test group } & Abbreviation & \multicolumn{1}{c}{ Brand } & $\begin{array}{c}\text { Batch number } \\
\text { Lot number }\end{array}$ & Manufacturers information \\
\hline Monolithic Zirconia & $\mathrm{MZ}(\mathrm{n}=8)$ & Zolid fx preshade & - & Amann Girrbach, Koblach, Austria \\
Lithium Disillicate & $\mathrm{LD}(\mathrm{n}=8)$ & IPS E.max & P15652 & Ivoclar Vivadent AG, Schaan, Principality of Liechtenstein \\
Ceramometal & $\mathrm{CM}(\mathrm{n}=8)$ & Porcelain fused to Metal & - & Ivoclar Vivadent AG, Schaan, Principality of Liechtenstein \\
Composite Resin & $\mathrm{CR}(\mathrm{n}=8)$ & Nano hybrid filtek z250 & N636355 & 3M ESPE, Dubai, United Arab Emirates \\
\hline
\end{tabular}

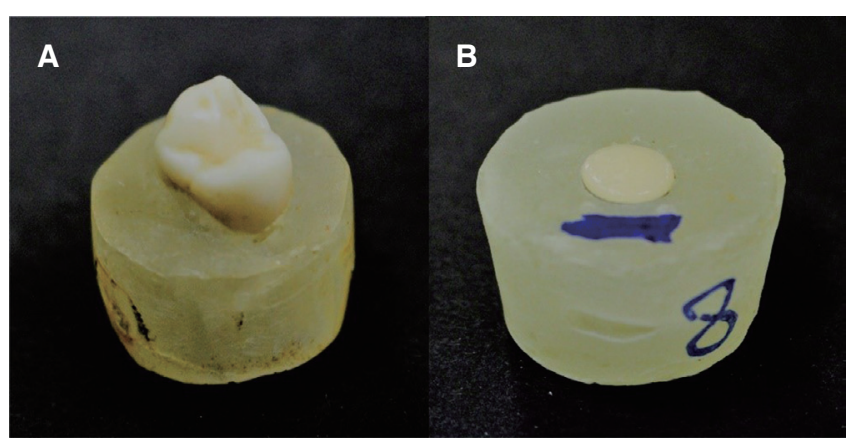

Fig. 1. (A) Mounted tooth specimen in resin block, (B) Disc shaped material specimen embedded in resin block.

were distributed equally to the four groups by random draw method.

For each of the four groups to be tested, eight samples of $10 \mathrm{~mm}$ diameter discs and a thickness of $3 \mathrm{~mm}$ were fabricated and glazed or polished according to the manufacturer's instructions. The discs were then cleaned in an ultrasonic bath for $10 \mathrm{~min}$ and were embedded in acrylic resin (Ortho-Resin, DeguDent GmbH, Hanau, Germany) mold to lock the samples in the chewing simulation machine (Fig. 1B).

A wear test was conducted using the chewing simulation machine (Chewing Simulator, CS-4.8 professional line, SD Mechatronik GMBH, Westerham, Germany). The machine has eight chambers simulating the vertical and horizontal chewing movements simultaneously in the thermodynamic condition (Fig. 2A). The specimens embedded in resin were fastened with a screw in the upper sample holder and the material specimens along with their resin blocks were fixed in the lower sample holder (Fig. 2B). A weight of $5 \mathrm{~kg}$, comparable to $49 \mathrm{~N}$ of chewing force was applied. According to previous studies, 240,000 - 250,000 loading cycles in a chewing simulator are comparable to approximately one-year chewing from a clinical perspective. The strokes repeated 240,000 times to clinically simulate one-year chewing condition. Accompanying the thermocycling with distal water, ${ }^{23}$ various parameters were adjusted such as: cold/hot bath

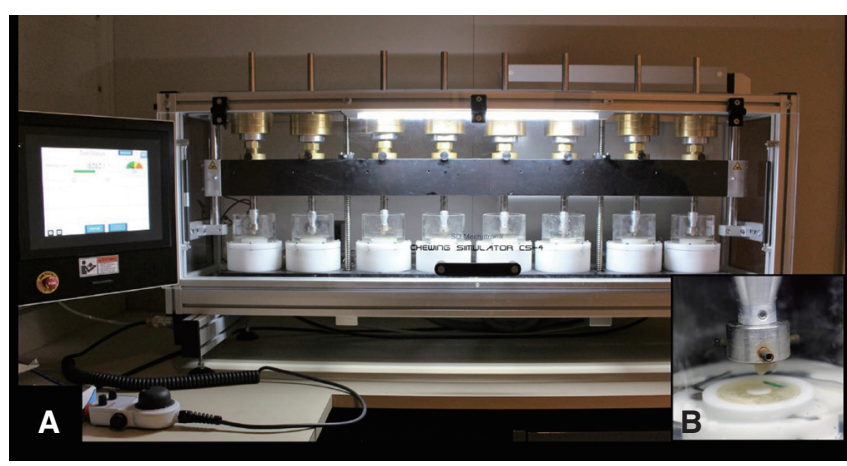

Fig. 2. (A) Specimens of one group locked in chewing simulation machine, (B) Close up picture of a material specimen along with antagonistic tooth enamel specimen.

temperature: $5^{\circ} \mathrm{C} / 55^{\circ} \mathrm{C}$; dwell time: $60 \mathrm{~s}$; vertical movement: $6 \mathrm{~mm}$; horizontal movement: $0.3 \mathrm{~mm}$; rising speed: $55 \mathrm{~mm} / \mathrm{s}$; forward speed: $30 \mathrm{~mm} / \mathrm{s}$; descending speed: 30 $\mathrm{mm} / \mathrm{s}$; backward speed: $55 \mathrm{~mm} / \mathrm{s}$; weight per sample: $5 \mathrm{~kg}$; cycle frequency: $0.8 \mathrm{~Hz}$; kinetic energy: 2,250 × 10-6 J.

Height, weight, and SR were recorded before and after subjecting the specimens to wear cycle.

Heights of all the specimens before and after the wear cycle were recorded by calculating the vertical occlusal wear using a digital caliper (Mitutoyo, 500-196-30 AOS, Absolute Caliper 0-6, Aurora, IL, USA) up to one hundredths of a millimeter $(0.01 \mathrm{~mm})$.

Weight measurement of all the specimens before and after the wear cycle were measured for quantitative loss using analytical balance (Analytical balance $220 \mathrm{~g} \times 0.1 \mathrm{mg}$ Radwag AS 220/C/2) up to one tenth of a milligram (0.1 mg).

Baseline SR and post-wear SR (Fig. 3) were determined in micrometers $(\mu \mathrm{m})$ for all the specimens using threedimensional (3D) profilometer (Contour-GT-X, 3D Optical Microscope, Bruker Nano Surfaces Division, San Jose, CA, USA). The 3D surfaces before and after the wear test were scanned using a 3D profiling system, and SR of the specimens were calculated using a 3D software (Vision64, Operation and Analysis Software, Bruker Nano Surfaces Division, San Jose, CA, USA).

For the qualitative characterization of wear patterns 

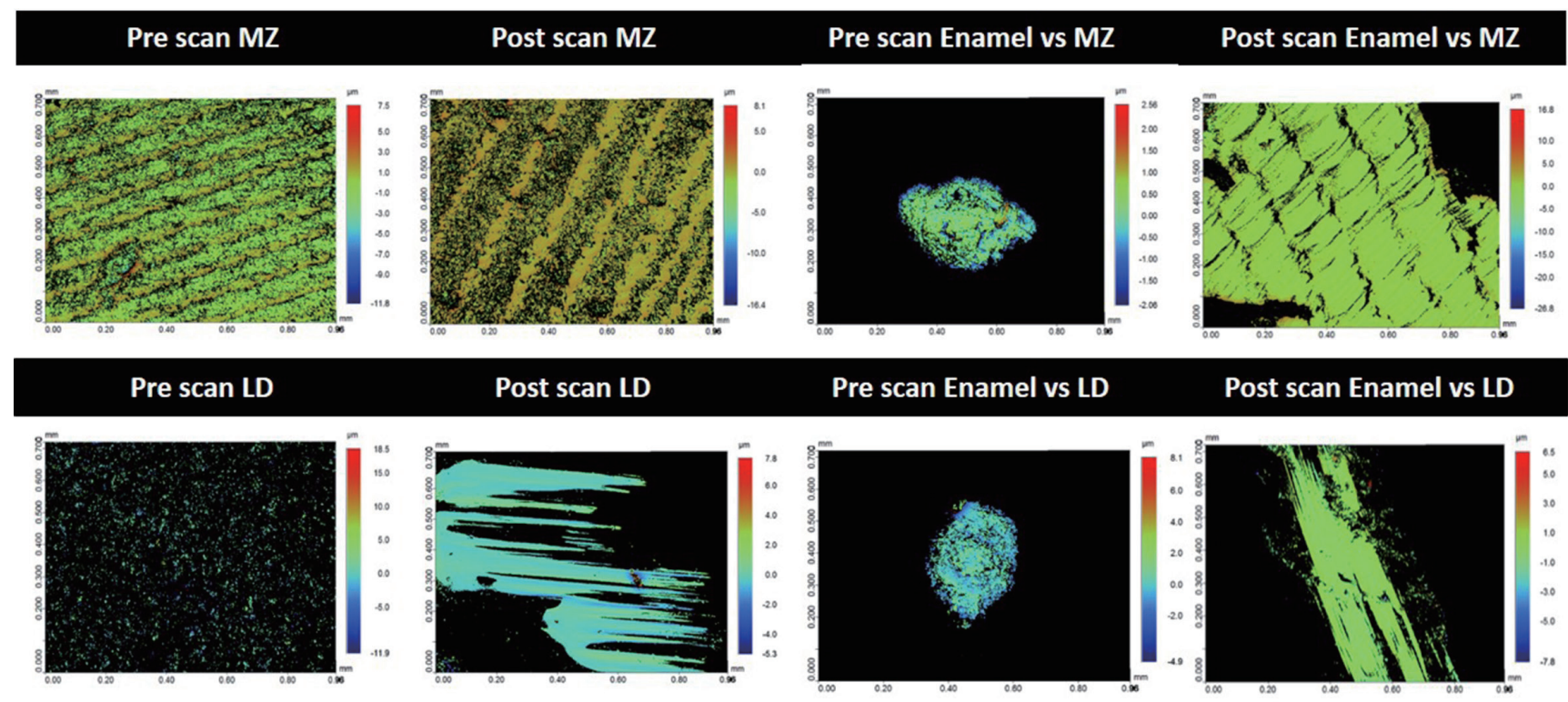

Post scan LD

Pre scan Enamel vs LD

Post scan Enamel vs LD
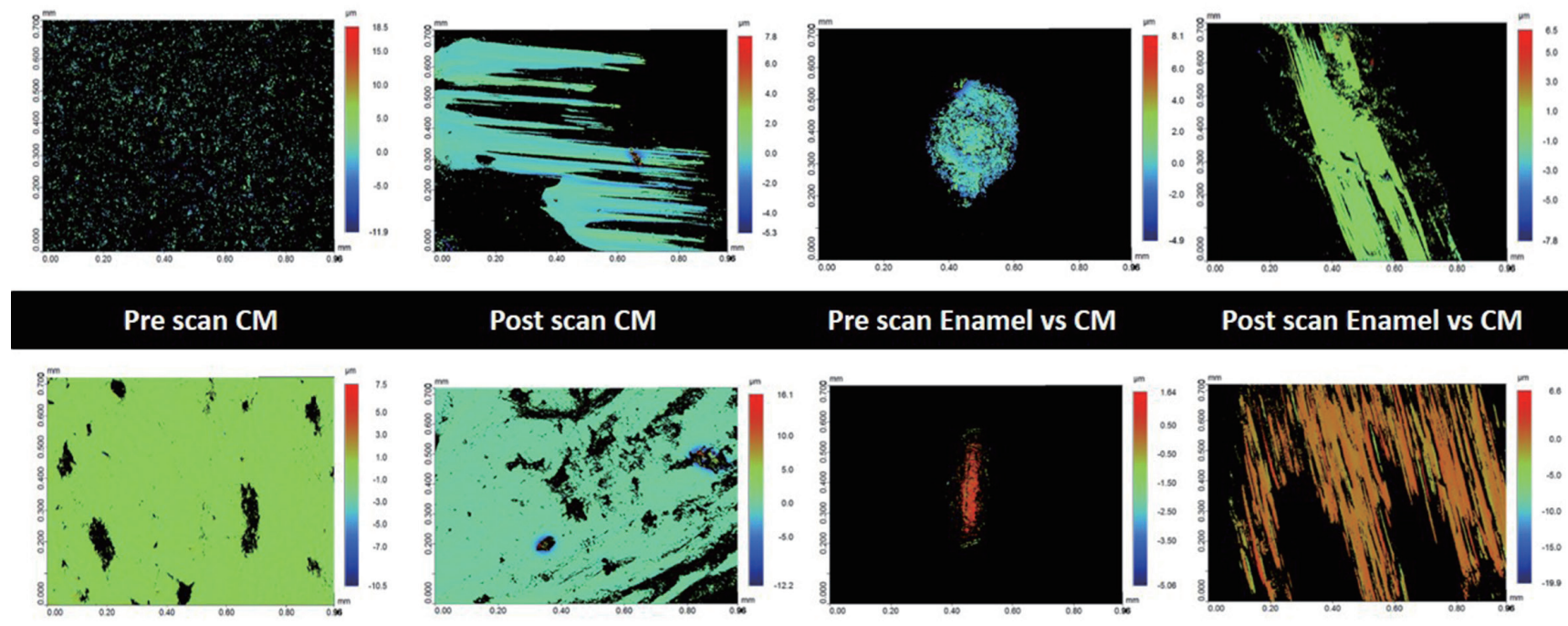

Post scan CM

Pre scan Enamel vs CM

Post scan Enamel vs CM
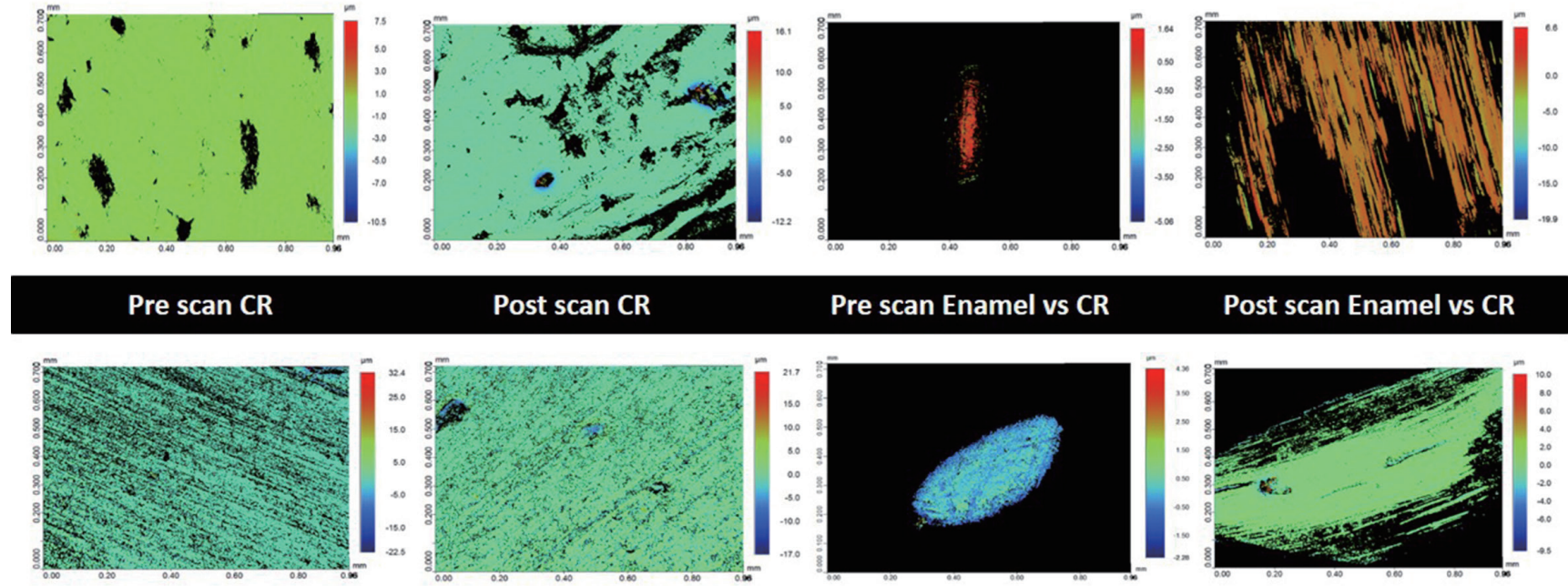

\section{Post scan CR}

Pre scan Enamel vs CR

Post scan Enamel vs CR

Fig. 3. Samples of pre and post 3D profilometer images for the tested materials; monolithic zirconia (MZ); lithium disilicate glass ceramic (LD); ceramometal (CM); composite resin (CR) and their antagonist enamel specimens.

(Fig. 4), all the specimens and enamel antagonists were evaluated with digital microscope (HIROX, KH-7700, Digital microscope system, Tokyo, Japan) before and after the wear cycle.

The mean and standard deviation of the test parameters were calculated using SPSS (Ver. 21.0, SPSS, Chicago, IL, USA). The statistical analysis included the descriptive statistics, Levene test for testing the homogeneity, Shapiro-Wilk test for testing the normality, comparisons of the mean difference pre and post wear cycle with Paired T-test, comparisons of the groups' means with one way ANOVA, and multiple comparisons among the groups with Post Hoc TukeyHSD test at a significance level of $P<.05$.

\section{RESULTS}

In the current research study SR, weight, and height of four restorative materials and their antagonist enamel were measured and compared. The measurements were recorded before (Pre) and after (Post) the samples were exposed to one year chewing simulation cycles. Normality of all the data was evaluated with Shapiro-Wilk test and found to be normally distributed for all the groups $(P \geq .05)$. Levene test for testing the equality of variance showed a value of 1.25 with $P=.290$, confirming the homogeneity of the data.

The overall mean SR values for the tested materials are presented in Table 2. CM had the least pre and post SR values of $0.14 \pm 0.03 \mu \mathrm{m}$ and $0.37 \pm 0.22 \mu \mathrm{m}$, respectively 


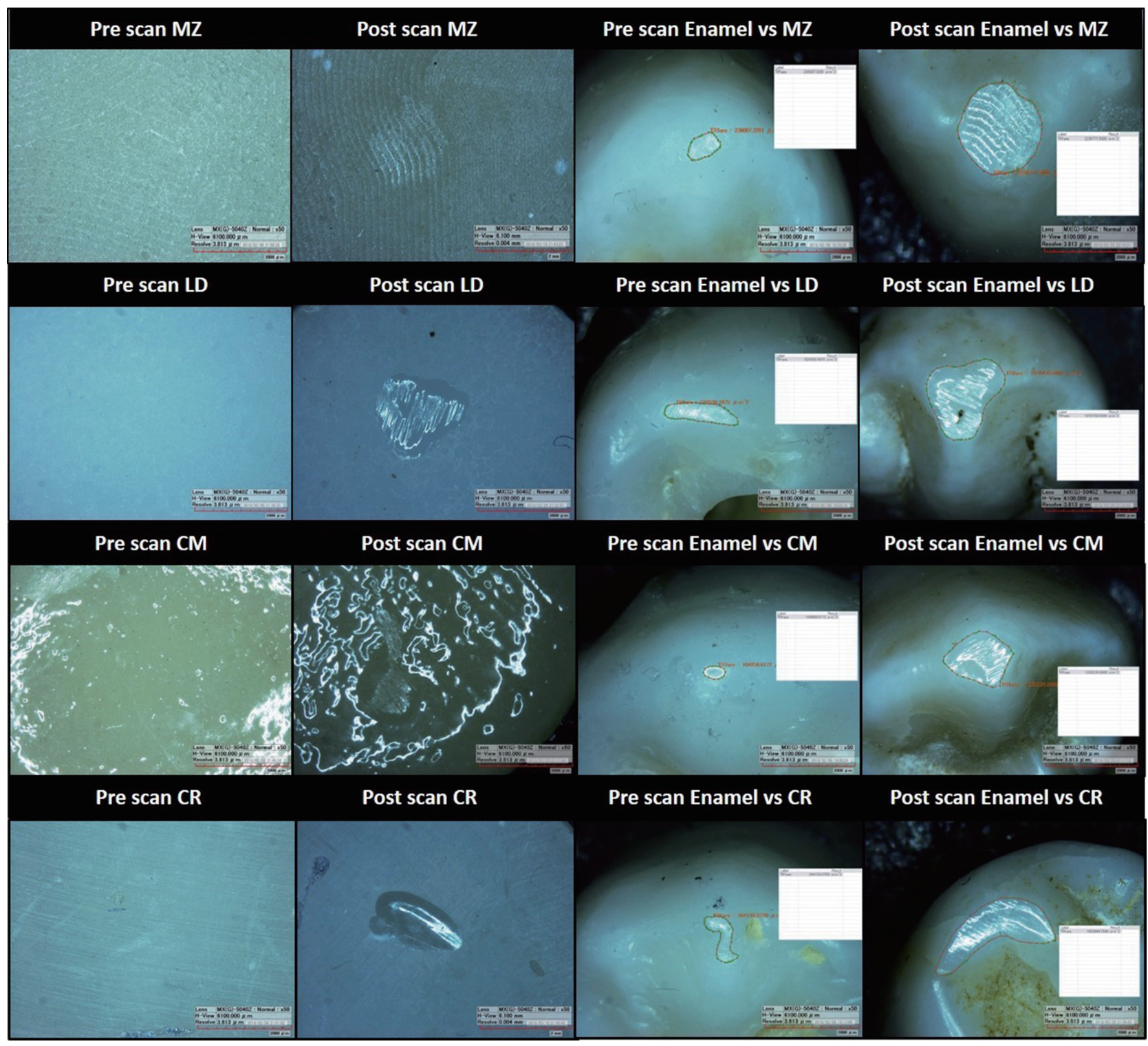

Fig. 4. Samples of pre and post digital microscopic images for the tested materials; monolithic zirconia (MZ); lithium disilicate glass ceramic (LD); ceramometal (CM); composite resin (CR) and their antagonist enamel specimens.

Table 2. Descriptive statistics and comparison with Paired T test of the pre and post wear of tested materials

\begin{tabular}{|c|c|c|c|c|c|c|c|}
\hline \multirow{2}{*}{ Test material } & \multirow{2}{*}{ SR } & \multirow{2}{*}{${ }^{\star}$ Mean (SD) } & \multirow{2}{*}{$\begin{array}{c}\text { Mean differences } \\
\text { (SD) }\end{array}$} & \multicolumn{2}{|c|}{$95 \% \mathrm{Cl}$} & \multirow{2}{*}{$\begin{array}{c}\text { Paired T Test } \\
P \text { value }\end{array}$} & \multirow{2}{*}{$\begin{array}{l}\text { ANOVA } \\
P \text { value }\end{array}$} \\
\hline & & & & Lower bound & Upper bound & & \\
\hline \multirow{2}{*}{$M Z(n=8)$} & Pre & $0.67(0.05)$ & \multirow{2}{*}{$0.29(0.18)$} & \multirow{2}{*}{.45} & \multirow{2}{*}{.13} & \multirow{2}{*}{.003} & \\
\hline & Post & $0.96(0.18)$ & & & & & \\
\hline \multirow{2}{*}{$\operatorname{LD}(n=8)$} & Pre & $0.35(0.13)$ & \multirow[t]{2}{*}{$0.68(0.16)$} & \multirow{2}{*}{.81} & \multirow{2}{*}{.54} & \multirow{3}{*}{.000} & \\
\hline & Post & $1.04(0.15)$ & & & & & \\
\hline \multirow{3}{*}{$\mathrm{CM}(\mathrm{n}=8)$} & & & & & & & .001 \\
\hline & Pre & $0.14(0.03)$ & \multirow{2}{*}{$0.23(0.08)$} & \multirow{2}{*}{.42} & \multirow{2}{*}{.03} & \multirow{2}{*}{.025} & \\
\hline & Post & $0.37(0.22)$ & & & & & \\
\hline \multirow{2}{*}{$\mathrm{CR}(\mathrm{n}=8)$} & Pre & $0.64(0.27)$ & \multirow{2}{*}{$0.38(0.24)$} & \multirow{2}{*}{.58} & \multirow{2}{*}{.17} & \multirow{2}{*}{.003} & \\
\hline & Post & $1.02(0.32)$ & & & & & \\
\hline
\end{tabular}

${ }^{*}$ Mean and standard deviation in micrometers $(\mu \mathrm{m})$. 
with the least mean difference of $0.23 \pm 0.08 \mu \mathrm{m}$. The highest mean SR difference of $0.68 \pm 0.16 \mu \mathrm{m}$ between pre $(0.35 \pm 0.13 \mu \mathrm{m})$ and post $(1.04 \pm 0.15 \mu \mathrm{m})$ values was exhibited by LD. One way analysis of variance of the logarithmic mean values was performed and revealed a significant difference among the material groups for the SR values. Comparison with Paired T-Test for the pre and post SR comparisons also revealed a significant difference for all the groups (Table 2).

Multiple comparison test (Post Hoc Tukey HSD) indicated that there was a statistically significant difference for LD from the other materials (Table 3).

Table 4 shows the overall mean SR values for the antagonistic enamel against each tested material. Compared to the variation in SR among the materials, the SR of their antagonistic enamel against the materials were very similar. This was confirmed by one way analysis of variance test showing a non-significant difference between the enamel SR and the tested materials. However, the pre and post SR values of all the enamel antagonists for each tested material revealed a significant difference with $P<.05$ ('Table 4).
Comparing the enamel SR for all the groups with Post Hoc Tukey HSD indicated insignificant differences for all the groups (Table 4).

The descriptive statistics of the weights of the materials tested and their corresponding enamel antagonists before and after the wear cycles are summarized in Table 5. The wear cycles had a significant effect on the enamel weight against all the materials $(P<.05)$, but it had no significance over all of the materials tested $(P>.05)$ (Table 5).

Table 3. Multiple comparisons of the wear differences between the 4 tested materials by Post Hoc Tukey HSD test*

\begin{tabular}{ccccc}
\hline Groups & MZ & LD & CM & CR \\
\hline MZ & - & .005 & .926 & .852 \\
LD & .005 & - & .001 & .038 \\
CM & .926 & .001 & - & .498 \\
CR & .852 & .038 & .498 & - \\
\hline
\end{tabular}

${ }^{*} P$ value was significant at $P<.05$.

Table 4. Descriptive statistics and comparison with Paired T test of the pre and post wear of enamel antagonist against tested materials

\begin{tabular}{|c|c|c|c|c|c|c|c|}
\hline \multirow{2}{*}{ Enamel against } & \multirow{2}{*}{$\mathrm{SR}$} & \multirow{2}{*}{${ }^{\star}$ Mean (SD) } & \multirow{2}{*}{$\begin{array}{c}\text { Mean differences } \\
\text { (SD) }\end{array}$} & \multicolumn{2}{|c|}{$95 \% \mathrm{Cl}$} & \multirow{2}{*}{$\begin{array}{c}\text { Paired T-test } \\
P \text { value }\end{array}$} & \multirow{2}{*}{$\begin{array}{l}\text { ANOVA } \\
P \text { value }\end{array}$} \\
\hline & & & & Lower bound & Upper bound & & \\
\hline \multirow{2}{*}{$M Z(n=8)$} & Pre & $0.50(0.24)$ & \multirow{2}{*}{$0.49(0.34)$} & \multirow{2}{*}{.73} & \multirow{2}{*}{.16} & \multirow{2}{*}{.007} & \\
\hline & Post & $0.95(0.37)$ & & & & & \\
\hline \multirow{3}{*}{$\operatorname{LD}(\mathrm{n}=8)$} & Pre & $0.42(0.07)$ & \multirow{3}{*}{$0.40(0.21)$} & \multirow{3}{*}{.58} & \multirow{2}{*}{.22} & \multirow{3}{*}{.001} & \\
\hline & Post & $0.82(0.22)$ & & & & & \\
\hline & & & & & & & .987 \\
\hline \multirow{2}{*}{$\mathrm{CM}(\mathrm{n}=8)$} & Pre & $0.47(0.12)$ & \multirow{2}{*}{$0.45(0.44)$} & \multirow{2}{*}{.83} & \multirow{2}{*}{.08} & \multirow{2}{*}{.024} & \\
\hline & Post & $0.93(0.51)$ & & & & & \\
\hline \multirow{2}{*}{$\mathrm{CR}(\mathrm{n}=8)$} & Pre & $0.36(0.11)$ & \multirow{2}{*}{$0.40(0.44)$} & \multirow{2}{*}{.77} & \multirow{2}{*}{.02} & \multirow{2}{*}{.039} & \\
\hline & Post & $0.76(0.45)$ & & & & & \\
\hline
\end{tabular}

${ }^{\star}$ Mean and standard deviation in micrometers $(\mu \mathrm{m})$.

Table 5. Descriptive statistics and comparison with Paired $T$ test of the pre and post weight of test materials and teeth specimens before and after the wear cycle

\begin{tabular}{|c|c|c|c|c|c|c|c|c|}
\hline \multirow{2}{*}{ Group } & \multicolumn{4}{|c|}{$\begin{array}{l}\text { Material weight } \\
{ }^{*} \text { Mean (SD) }\end{array}$} & \multicolumn{4}{|c|}{$\begin{array}{l}\text { Enamel weight } \\
{ }^{*} \text { Mean (SD) }\end{array}$} \\
\hline & Pre & Post & $\begin{array}{c}\text { Mean } \\
\text { difference }\end{array}$ & $P$ value & Pre & Post & $\begin{array}{c}\text { Mean } \\
\text { difference }\end{array}$ & $P$ value \\
\hline$M Z(n=8)$ & $17.98(0.33)$ & $17.69(0.37)$ & $0.28(0.46)$ & .124 & $4.49(0.27)$ & $3.81(0.37)$ & $0.67(0.36)$ & .001 \\
\hline $\operatorname{LD}(n=8)$ & $16.83(0.43)$ & $16.60(0.24)$ & $0.22(0.38)$ & .136 & $4.47(0.27)$ & $4.01(0.42)$ & $0.46(0.42)$ & .018 \\
\hline $\mathrm{CM}(\mathrm{n}=8)$ & $17.49(0.24)$ & $17.29(0.20)$ & $0.20(0.30)$ & .105 & $4.57(0.24)$ & $4.06(0.34)$ & $0.51(0.20)$ & .000 \\
\hline $\mathrm{CR}(\mathrm{n}=8)$ & $17.10(0.54)$ & $16.82(0.63)$ & $0.28(0.46)$ & .125 & $4.52(0.22)$ & $3.86(0.19)$ & $0.65(0.10)$ & .000 \\
\hline
\end{tabular}

${ }^{\star}$ Mean weight was measured in milligrams $(\mathrm{mg})$. 


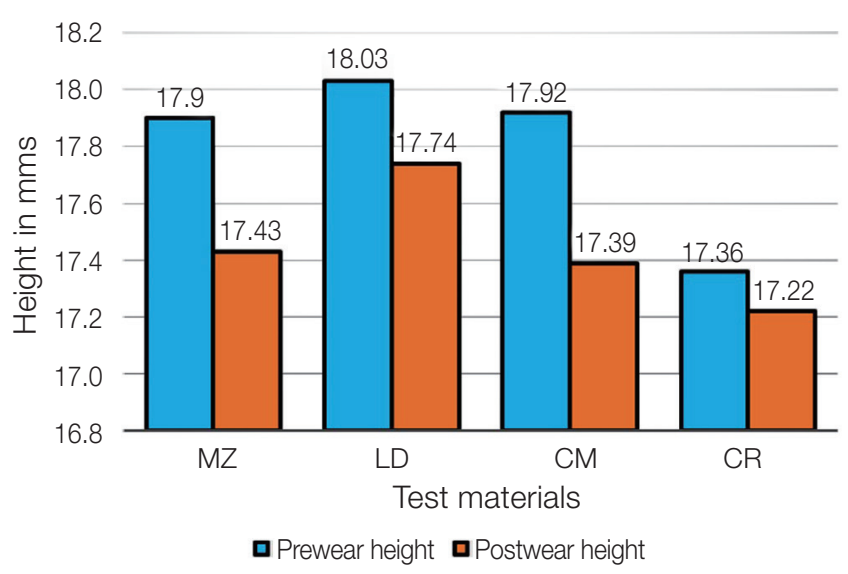

Fig. 5. Graphical comparison of Pre and Post height of teeth specimens against tested materials.

Graphical comparison of the pre and post height of the teeth against the tested materials is presented in Figure 5. $\mathrm{CR}$ and $\mathrm{MZ}$ had the lowest and the highest height loss of $0.14 \mathrm{~mm}$ and $0.46 \mathrm{~mm}$ among the groups, respectively.

\section{DISCUSSION}

In this in vitro research study, the two body wear behaviors (SR, weight, and height) of four commonly used restorative materials and their antagonistic natural tooth enamel were evaluated before and after aging in a chewing simulator. Test specimens of identical shape and dimensions were used under the same testing conditions. The two body chewing machine simulated the masticatory cycle by providing a combined sliding action of the test materials and the enamel against each other. ${ }^{23}$

In the current study, using a 3D non-contact profilometer for measuring the SR parameters offers good resolution of the traced surface and has been reported to be the optimal method for measurement of SR by several researchers. ${ }^{3,5-8}$ The SR parameter remains as a helpful general guideline of surface topography, providing a useful and easy-tounderstand value, which makes possible the SR comparison of different materials and result comparison with other literature and standards. ${ }^{13}$

In the literature, some works confirmed the difference in wear behavior of various restorative materials opposing natural teeth enamel with standardized in vitro wear simulation at different time intervals. ${ }^{7,8}$ Most wear tests provide only limited or no correlation with the clinical data ${ }^{27}$, even though they allow a comparative evaluation of different materials under standardized testing conditions. Therefore, testing conditions close to the clinical situations are preferable. A chewing force of $50 \mathrm{~N}$, applied with a frequency of 1 - 1.6 Hz, presents the average mastication load and is commonly used for oral simulation. ${ }^{28,29}$ With this method, it is expected that permanent thermal cycling with water removes wear debris from the specimen's surface and the specimens are kept wet during the whole course of the test, which may cause additional aging of the specimens. ${ }^{30}$

According to the results of the current study, significant variations in the SR for the materials were observed. In contrast, the antagonistic enamel specimen showed minor and insignificant variations against each restorative material. Thus, based on the results, the null hypothesis of no wear difference among the materials after the wear simulation was rejected and the null hypothesis of no wear difference of their opposing enamel was accepted.

The results of the current study indicate that the $\mathrm{MZ}$ created the highest enamel surface roughness, followed by CM. LD and CR showed the least and similar SR of their opposing enamel, respectively. However, this variation was not statistically significant. The high SR and wear of antagonistic teeth by the CM (veneered feldspathic porcelain) have also been reported by Etman et al. ${ }^{31}$ and EsquivelUpshaw et al.. ${ }^{32} \mathrm{MZ}$ was introduced to overcome the complications of chipping, fracture of the veneering ceramic, and wear of the opposing enamel due to veneering ceramic. ${ }^{5,33}$ Although the results of the current study showed a high enamel SR caused by the MZ compared to other tested materials, the difference is in hundredths of a micrometer. It can be concluded that for $\mathrm{MZ}$ the $\mathrm{SR}$ rates for enamel are in consensus with the SR rates for other tested materials. Similar findings were reported by Lohbauer and Reich ${ }^{34}$ in a recent research study.

In the present study, different levels of SR were observed for the restorative materials investigated. The lowest SR was found for CM and MZ, which can be related to their hardness. The surface hardness value of veneering ceramics (420 HV) and zirconia $(1250 \mathrm{HV})$ respectively are very high and will cause more abrasion of the opposing enamel. ${ }^{33,36}$ This may be related to the increased enamel SR against these hard materials.

Comparing the weight loss of the tested materials and the antagonistic enamel showed increased weight loss for the enamel specimens. The differences could be due to the differences in the composition and microstructure of the dental materials and dental hard tissues. ${ }^{37}$ The highest weight loss was found for the $\mathrm{MZ}$ specimens $(0.28 \pm 0.46$ $\mathrm{mg})$ and their antagonistic enamel specimens $(0.67 \pm 0.36$ $\mathrm{mg})$. This finding further explains the increased wear of the enamel against the MZ. Another interesting finding was that CR showed behavior similar to $\mathrm{MZ}$ of the material $(0.28 \pm$ $0.46 \mathrm{mg})$ and enamel loss $(0.65 \pm 0.10 \mathrm{mg})$. According to the general knowledge, a softer material is abraded more easily against a harder material. Logically the enamel wear caused by the CR should be less. ${ }^{9}$ However, this supposition was not supported by the results of the current study. The possible explanation of this phenomenon could be related to the wear behavior of CR, which is different from that of the brittle materials (ceramic or zirconia), and hardness alone cannot be used as a wear predictor. ${ }^{7}$ Another possible reason for CR causing more wear of the opposing enamel in this study could be related to its pre wear SR values $(0.64$ 
\pm 0.27 ), which were the second highest among the test materials. The high SR could be due to the chairside polishing of the $\mathrm{CR}$ while the other materials received high quality glaze within the dental laboratory.

In vitro wear studies have shortcomings and lack evidence of clinical relevance. For example, they evaluate wear behavior by simulation of only one or two wear mechanisms under limited chewing simulation conditions. ${ }^{36}$ In simulation tests, enamel antagonists are required to present clinical conditions. However, morphological and structural differences of enamel complicate standardized wear testing that may cause high variations in the wear data. ${ }^{37}$ Another important difference between the clinical studies and laboratory studies related to wear is that ceramic crowns are often adjusted with a diamond bur and then re-polished or re-glazed prior to cementation. ${ }^{38}$

In this study, the wear results varied within each group. This variation could be attributed to the inhomogeneity in the enamel antagonists. Human tooth tissues show variations in geometry or thickness of enamel layers and may become brittle due to storage conditions. ${ }^{37}$ The results of the current study should be interpreted with caution because of the above mentioned limitations.

Suggestions for future studies include usefulness of any diagnostic methods for in vivo assessment of wear behavior of the restorative materials and their opposing enamel antagonists.

Further clinical studies with larger sample size are required, with similar and standardized methodologies to investigate and verify the wear behavior of these materials.

\section{CONCLUSION}

Monolithic zirconia and ceramometal are more resistant to wear against the enamel than lithium disilicate and composite resin. The enamel specimens worn by the tested materials showed similar surface roughness values with monolithic zirconia and ceramometal causing slightly increased surface roughness than lithium disilicate and composite resin. Significant variations in surface roughness values for the tested materials (monolithic zirconia, ceramometal, lithium disilicate, and composite resin) against the enamel were found. The wear cycles had a significant effect on the enamel weight loss against all the materials. The enamel antagonist against monolithic zirconia and ceramometal showed more vertical height loss compared to lithium disilicate and composite resin after the wear cycle.

\section{ACKNOWLEDGEMENTS}

The authors are thankful to Mr. Bong for assistance with Digital Microscopic measurements and Mr. Nassr Maflehi for his help in the statistical analysis.

\section{ORCID}

Syed Rashid Habib https://orcid.org/0000-0002-4398-3479

\section{REFERENCES}

1. Lucas PW, Omar R, Al-Fadhalah K, Almusallam AS, Henry AG, Michael S, Thai LA, Watzke J, Strait DS, Atkins AG. Mechanisms and causes of wear in tooth enamel: implications for hominin diets. J R Soc Interface 2013;10:20120923.

2. Xia J, Zheng J, Huang D, Tian ZR, Chen L, Zhou Z, Ungar PS, Qian L. New model to explain tooth wear with implications for microwear formation and diet reconstruction. Proc Natl Acad Sci USA 2015;112:10669-72.

3. Mundhe K, Jain V, Pruthi G, Shah N. Clinical study to evaluate the wear of natural enamel antagonist to zirconia and metal ceramic crowns. J Prosthet Dent 2015;114:358-63.

4. Clelland NL, Agarwala V, Knobloch LA, Seghi RR. Wear of enamel opposing low-fusing and conventional ceramic restorative materials. J Prosthodont 2001;10:8-15.

5. Heintze SD, Cavalleri A, Forjanic M, Zellweger G, Rousson V. Wear of ceramic and antagonist-a systematic evaluation of influencing factors in vitro. Dent Mater 2008;24:433-49.

6. Wang L, Liu Y, Si W, Feng H, Tao Y, Ma Z. Friction and wear behaviors of dental ceramics against natural tooth enamel. J Eur Ceram Soc 2012;32:2599-606.

7. Sripetchdanond J, Leevailoj C. Wear of human enamel opposing monolithic zirconia, glass ceramic, and composite resin: an in vitro study. J Prosthet Dent 2014;112:1141-50.

8. Zandparsa R, El Huni RM, Hirayama H, Johnson MI. Effect of different dental ceramic systems on the wear of human enamel: An in vitro study. J Prosthet Dent 2016;115:230-7.

9. Shimane T, Endo K, Zheng JH, Yanagi T, Ohno H. Wear of opposing teeth by posterior composite resins-evaluation of newly developed wear test methods. Dent Mater J 2010;29: 713-20.

10. Yesil ZD, Alapati S, Johnston W, Seghi RR. Evaluation of the wear resistance of new nanocomposite resin restorative materials. J Prosthet Dent 2008;99:435-43.

11. Bartlett D, Varma S. A retrospective audit of the outcome of composites used to restore worn teeth. Br Dent J 2017;223: 33-6.

12. Borgia E, Baron R, Borgia JL. Quality and survival of direct light-activated composite resin restorations in posterior teeth: A 5- to 20-year retrospective longitudinal study. J Prosthodont 2017 May 17.

13. Ho TK, Satterthwaite JD, Silikas N. The effect of chewing simulation on surface roughness of resin composite when opposed by zirconia ceramic and lithium disilicate ceramic. Dent Mater 2018;34:e15-e24.

14. Denry I, Holloway JA. Ceramics for dental applications: A review. Materials 2010;3:351-68.

15. Araujo NS, Moda MD, Silva EA, Zavanelli AC, Mazaro JV, Pellizzer EP. Survival of all-ceramic restorations after a minimum follow-up of five years: A systematic review. Quintessence Int 2016;47:395-405.

16. Ren L, Zhang Y. Sliding contact fracture of dental ceramics: Principles and validation. Acta Biomater 2014;10:3243-53.

17. Arsecularatne JA, Chung NR, Hoffman M. An in vitro study of the wear behaviour of dental composites. Biosurf Biotribol 2016;2:102-13. 
18. Zhao X, Pan J, Zhang S, Malmstrom HS, Ren YF. Effectiveness of resin-based materials against erosive and abrasive enamel wear. Clin Oral Investig 2017;21:463-8.

19. Fischer TE, Anderson MP, Jahanmir S. Influence of fracture toughness on the wear resistance of yttria-doped zirconium oxide. J Am Ceram Soc 1989;72:252-7.

20. Mitov G, Heintze SD, Walz S, Woll K, Muecklich F, Pospiech P. Wear behavior of dental Y-TZP ceramic against natural enamel after different finishing procedures. Dent Mater 2012;28:909-18.

21. Mörmann WH, Stawarczyk B, Ender A, Sener B, Attin T, Mehl A. Wear characteristics of current aesthetic dental restorative CAD/CAM materials: two-body wear, gloss retention, roughness and Martens hardness. J Mech Behav Biomed Mater 2013;20:113-25.

22. Rosentritt M, Preis V, Behr M, Hahnel S, Handel G, Kolbeck C. Two-body wear of dental porcelain and substructure oxide ceramics. Clin Oral Investig 2012;16:935-43.

23. Stawarczyk B, Özcan M, Schmutz F, Trottmann A, Roos M, Hämmerle CH. Two-body wear of monolithic, veneered and glazed zirconia and their corresponding enamel antagonists. Acta Odontol Scand 2013;71:102-12.

24. Stawarczyk B, Frevert K, Ender A, Roos M, Sener B, Wimmer T. Comparison of four monolithic zirconia materials with conventional ones: Contrast ratio, grain size, four-point flexural strength and two-body wear. J Mech Behav Biomed Mater 2016;59:128-38.

25. Mitov G, Heintze SD, Walz S, Woll K, Muecklich F, Pospiech P. Wear behavior of dental Y-TZP ceramic against natural enamel after different finishing procedures. Dent Mater 2012;28:909-18.

26. Janyavula S, Lawson N, Cakir D, Beck P, Ramp LC, Burgess JO. The wear of polished and glazed zirconia against enamel. J Prosthet Dent 2013;109:22-9.

27. Heintze SD. How to qualify and validate wear simulation devices and methods. Dent Mater 2006;22:712-34.

28. Preis V, Behr M, Kolbeck C, Hahnel S, Handel G, Rosentritt M. Wear performance of substructure ceramics and veneering porcelains. Dent Mater 2011;27:796-804.

29. Rosentritt M, Behr M, van der Zel JM, Feilzer AJ. Approach for valuating the influence of laboratory simulation. Dent Mater 2009;25:348-52.

30. Hahnel S, Behr M, Handel G, Rosentritt M. Two-body wear of artificial acrylic and composite resin teeth in relation to antagonist material. J Prosthet Dent 2009;101:269-78.

31. Etman MK, Woolford M, Dunne S. Quantitative measurement of tooth and ceramic wear: in vivo study. Int J Prosthodont 2008;21:245-52.

32. Esquivel-Upshaw J, Rose W, Oliveira E, Yang M, Clark AE, Anusavice K. Randomized, controlled clinical trial of bilayer ceramic and metal-ceramic crown performance. J Prosthodont 2013;22:166-73.

33. Passos SP, Torrealba Y, Major P, Linke B, Flores-Mir C, Nychka JA. In vitro wear behavior of zirconia opposing enamel: a systematic review. J Prosthodont 2014;23:593-601.

34. Lohbauer U, Reich S. Antagonist wear of monolithic zirconia crowns after 2 years. Clin Oral Investig 2017;21:1165-72.
35. Chun KJ, Lee JY. Comparative study of mechanical properties of dental restorative materials and dental hard tissues in compressive loads. J Dent Biomech 2014;5:1758736014555246.

36. Hmaidouch R, Weigl P. Tooth wear against ceramic crowns in posterior region: a systematic literature review. Int J Oral Sci 2013;5:183-90.

37. Zhang YR, Du W, Zhou XD, Yu HY. Review of research on the mechanical properties of the human tooth. Int J Oral Sci 2014;6:61-9.

38. Vieira AC, Oliveira MC, Lima EM, Rambob I, Leite M. Evaluation of the surface roughness in dental ceramics submitted to different finishing and polishing methods. J Indian Prosthodont Soc 2013;13:290-5. 